Cadernos de Pesquisa do CDHIS

\title{
A moça moderna nas Fotografias da Escola de Economia Rural Doméstica de Uberaba (ESERD)
}

The modern girl in the Photographs of the School of Domestic Rural Economy in Uberaba (ESERD)

Juno Alexandre Vieira Carneiro ${ }^{1}$

\footnotetext{
${ }^{1}$ Historiador, Técnico em Arquivo - Instituto Federal de Educação, Ciência e Tecnologia do Triângulo Mineiro (IFTM) Campus Uberaba. Mestre em Educação Tecnológica pelo IFTM Campus Uberaba. E-mail: junovieira@iftm.edu.br.
} 


\section{RESUMO}

Discutem-se os lugares e papeis sociais reservados à figura feminina na ESERD, por meio do estudo das fotografias produzidas pela instituição e preservadas no arquivo histórico do IFTM. Nesse sentido, percebe-se uma situação pendular, ora estimulando a emancipação das alunas, de forma a contribuírem para o desenvolvimento econômico através da gestão científica do lar e da família, ora limitando-as, mediante a manutenção de valores tradicionais com vistas à reprodução de padrões éticos e morais.

Palavras-chave:

ESERD.

fotografia. moça moderna. arquivo

\section{ABSTRACT}

The places and social roles reserved for the female figure at ESERD are discussed, through the study of the photographs produced by the institution and preserved in the IFTM historical archive. In this sense, a pendular situation is perceived, sometimes encouraging the emancipation of the students, in order to contribute to economic development through the scientific management of the home and family, sometimes limiting them, by maintaining traditional values with a view to reproduction ethical and moral standards.

Keywords: ESERD. photography. modern girl. archive 
Este texto integra os resultados de uma pesquisa de Mestrado Profissional em Educação Tecnológica no Instituto Federal de Educação, Ciência e Tecnologia do Triângulo Mineiro (IFTM), e tem como objetivo discutir os lugares e papeis sociais reservados à figura feminina na Escola de Economia Rural Doméstica de Uberaba (ESERD), sob a perspectiva dos registros fotográficos da instituição entre os anos 1954-1978. ${ }^{2}$

A escola orientou-se à educação feminina para o trabalho doméstico, mediante o domínio de técnicas e habilidades alicerçadas nos conhecimentos práticos necessários à população rural ou urbana, desenvolvendo os costumes, condutas e condições de vida (FERREIRA, 2014, p. 208). As fotografias da ESERD preservadas no arquivo histórico do IFTM somam cerca de quinhentos registros, dos quais doze foram escolhidos para a elaboração deste texto. São imagens sobre o cotidiano escolar, que representam atividades pedagógicas e momentos de comemoração e celebração, de forma a contemplar as temáticas recorrentes acerca da trajetória da ESERD ${ }^{3}$. Dessa forma, qual o perfil da moça moderna atendida pela instituição e representada nas imagens fotográficas, estimulada a incorporar a mentalidade pautada no aprendizado de critérios científicos e racionais, mas circunscrita aos padrões éticos e morais vigentes à época?

\footnotetext{
${ }^{2}$ A ESERD foi criada no ano de 1953, por iniciativa do Padre Agostinho Zago, vinculada à Superintendência do Ensino Agrícola e Veterinário (SEAV). Por força do Decreto no 83.935, de 04 de setembro de 1979, passou a denominar-se Escola Agrotécnica Federal de Uberaba (EAFU). Em 2002, transformou-se em Centro Federal de Educação Tecnológica de Uberaba e, por meio da Lei no 11.892/2008, foram criados 38 Institutos Federais de Educação, Ciência e Tecnologia, dentre os quais o IFTM - Campus Uberaba. Conferir: (LEMES, 2016).

${ }^{3}$ As fotografias integram o arquivo histórico do IFTM - Campus Uberaba, sediado no Setor de Arquivo da instituição. Em linhas gerais, o acervo contém planos de aula, ofícios, atas, correspondências, projetos pedagógicos, legislação, boletins de serviço e documentos alusivos ao cotidiano escolar, tais como: comemorações, eventos acadêmicos e extensionistas, premiações e formaturas, publicações técnicas e científicas, dentre outros, produzidos por professores, funcionários, alunos, imprensa e instituições das esferas pública e privada.
} 
Para tal, o texto subdivide-se em duas seções. Inicialmente, são discutidos os sentidos da expressão moça moderna, mediante às origens e especificidades da ESERD enquanto instituição vocacionada à formação em economia rural doméstica. Finalmente, na segunda seção, são analisados os lugares e papeis sociais das alunas sob a perspectiva dos registros fotográficos produzidos no decurso da primeira fase de atividades da escola.

\section{Uma escola para a moça moderna}

O Jornal Lavoura e Comércio, em edição do dia 08 de agosto de 1953 divulgou a criação da Escola de Economia Rural Doméstica em Uberaba, nos seguintes termos:

Será solenemente instalada amanhã, nesta cidade, à Rua Major Eustáquio, 88, a Escola de Economia Doméstica. A imponente cerimônia [...] assinala relevante conquista para esta comuna e toda a região, considerando os apreciáveis serviços que o estabelecimento prestará a Uberaba e ao Triângulo Mineiro. A finalidade da instituição, de que em boa hora foi enriquecido o patrimônio educacional e cultural de nossa terra, é a preparação da mulher, notadamente a da zona rural, para os trabalhos caseiros (LAVOURA E COMÉRCIO, 1953, p. 01).

Nas próximas linhas são destacados os esforços de personalidades locais, da igreja católica e dos representantes do governo federal para a instalação da escola. A matéria ainda descreve as repercussões da inauguração, em vista dos pedidos de inscrição provenientes de outras regiões do Estado e até mesmo de outros Estados da Federação. Por fim, o jornal menciona que a escola é a 
segunda instituição do gênero no país, o que teria despertado a procura por vagas para além das fronteiras municipais ${ }^{4}$.

Mas afinal, por que a conquista de uma escola vocacionada à formação em Economia Rural Doméstica teria sido relevante naquele contexto de meados do século XX? A esse respeito, Nilce Vieira Campos Ferreira (2014) nos apresenta estudo detalhado sobre a ESERD, que consistiu em analisar as estruturas da educação profissional em Economia Doméstica entre os anos de 1953 e 1997, período de funcionamento do curso, com o "intuito de delinear a formação para o trabalho como prática central e fundante das atividades pedagógicas" (FERREIRA, 2014, p. 29). Para a autora, as origens da ESERD vinculam-se às concepções da educação em circulação naquele momento, resultantes de sensíveis transformações sociohistóricas que culminaram em variados projetos educativos voltados à modernização da educação brasileira, estimulados pelas novas configurações do mundo do trabalho e das migrações campo-cidade ${ }^{5}$. Fenômenos tais como a urbanização, o consumo de massas e as inovações tecnológicas desencadearam transformações nas formas de vida das famílias, sinalizando para um futuro marcado por mudanças significativas.

Por certo, a década de 1950 coincide com um período de ascensão da classe média motivado pelo fim da segunda guerra mundial, em que imagens de esperança e otimismo atreladas à expansão urbana e à industrialização convergem para o incremento das possibilidades educacionais de homens e

\footnotetext{
${ }^{4}$ Segundo Ferreira, o primeiro curso de Economia Doméstica foi implantado no Brasil em 1952, pela Universidade Rural do Estado de Minas Gerais, atual Universidade Federal de Viçosa (UFV), como desdobramento dos acordos de cooperação técnica com os Estados Unidos, (FERREIRA, 2014, p. 155).

${ }^{5}$ As transformações apoiaram-se em projetos de nação em disputa no período 1930 a 1964, a saber: o nacional-populismo varguista representado por setores progressistas da sociedade brasileira que defendiam a industrialização sem o comprometimento da soberania nacional; e o projeto das oligarquias vinculadas ao setor agrário-exportador, que defendiam um modelo de desenvolvimento econômico subordinado à liderança dos Estados Unidos da América. Sobre isso, consultar: (BITTAR; BITTAR, 2012, p. 157).
} 
mulheres. Democracia e participação, entoadas em discursos políticos, materializam-se em melhorias nas condições de acesso à informação, ao lazer e ao consumo, (BASSANEZI, 2004, p. 508-509). Quanto ao lugar e o papel da educação para o trabalho em meio às transformações mencionadas:

Ao migrarem, as famílias rurais se instalaram nas periferias das cidades, o que aumentou a demanda por cursos nas áreas de desenvolvimento e educação familiar, educação infantil, segurança alimentar, programas de saúde e práticas agrícolas, entre outros. Dessa forma, as instituições governamentais tiveram que instituir espaços de formação para essa população (FERREIRA, 2014, p. 192).

A ESERD foi um desses espaços, iniciando as atividades em 1953 na cidade de Uberaba. Em linhas gerais, as articulações entre o Ministério da Agricultura, representantes da elite ruralista local e a Igreja Católica contribuíram para a instalação da escola, inspirada no trabalho feminino voltado à gestão do lar. A ESERD funcionou como Centro de Treinamento em Economia Rural Doméstica no ano de 1953 e em 1954 implantou o curso de magistério em Economia Rural Doméstica. Ambos enfatizavam as dimensões práticas e extensionistas como eixos formativos, fundamentadas nas concepções pedagógicas das escolas norte- americanas ${ }^{6}$.

Por conseguinte, qual o perfil da moça moderna ${ }^{7}$ atendida pela ESERD? Ferreira (2014, p. 208) refere-se a alunas de famílias abastadas provenientes das

\footnotetext{
${ }^{6}$ Ferreira destaca que desde a criação em 1953 a escola passou por várias transformações, com o propósito de atender às concepções educativas alinhadas às políticas públicas de governo. Sobre esse aspecto, a autora apresenta quadro sinótico detalhado com as modalidades dos cursos oferecidos na ESERD. Ainda que tenham ocorrido mudanças, as dimensões práticas e extensionistas foram preservadas, (FERREIRA, 2014, p. 241-243).

${ }^{7}$ Os sentidos da expressão moça moderna dizem respeito às transformações da sociedade brasileira naquele contexto, pois: "Cresceu na década de cinquenta a participação feminina no mercado de trabalho, especialmente no setor de serviços de consumo coletivo, em escritórios, no comércio ou em serviços públicos [...] Essa tendência demandou uma maior escolaridade feminina e provocou, sem dúvida, mudanças no status social das mulheres".
} 
regiões do Triângulo Mineiro e de várias partes do país. Percebemos as aproximações com a notícia do jornal Lavoura e Comércio que introduz essa seção. No entanto, para a autora, poucas alunas vinham do meio rural, em contraste com a afirmação daquele periódico que dizia se tratar de uma escola preparatória para os trabalhos caseiros, voltada às moças da zona rural.

\begin{abstract}
Ainda assim, elas deveriam adquirir durante o curso uma capacidade de planejar o emprego de recursos naturais para suprir as necessidades do lar. Com a aquisição de técnicas e habilidades úteis à vida, elas encontrariam fundamentação para os conhecimentos práticos necessários à população rural ou urbana, melhorando seus costumes, sua conduta, suas condições de vida (FERREIRA, 2014, p. 208).
\end{abstract}

Há nessa passagem o sentido de ruptura com uma tradição pautada no conhecimento intuitivo, na transmissão geracional, pois estava em curso a aplicação de preceitos científicos como norteadores da vida familiar. De fato, as disciplinas teóricas e práticas ministradas pela ESERD circunscreviam áreas do conhecimento voltadas à saúde, administração, psicologia, design, economia, culinária, artes, ética e moral dentre outras, adaptadas para a aplicação direta no cotidiano ${ }^{8}$. À moça moderna cabia então incorporar a mentalidade pautada no conhecimento científico facilmente aplicável na gestão do lar que se transformava com a inserção de produtos e equipamentos resultantes do boom dos bens de consumo da sociedade capitalista.

No entanto, os papeis femininos e masculinos ajustavam-se aos modelos societários vigentes à época. Ao homem era reservado o espaço público, o

Entretanto, conviviam as contradições entre as "visões tradicionais sobre os papéis femininos com a nova realidade que atraía as mulheres para o mercado de trabalho, a obtenção de uma maior independência e a possibilidade de satisfazer crescentes necessidades de consumo pessoal e familiar", (BASSANEZI, 2004, p.521- 522).

${ }^{8}$ Estudo detalhado sobre os currículos e as especificidades das disciplinas ofertadas na instituição encontra-se em: (FERREIRA, 2014, p. 245-277). 
mundo da rua, as ocupações profissionais tipicamente masculinas. Além disso, ele era o provedor, o guardião da estabilidade familiar. Dessa forma, "a moral sexual diferenciada permanecia forte e o trabalho da mulher, ainda que cada vez mais comum, era cercado de preconceitos e visto como subsidiário ao trabalho do homem, o chefe da casa", (BASSANEZI, 2004, p. 509). Esta autora sustenta que o Brasil incorporou, à sua maneira, as transformações internacionais quanto à emancipação feminina impulsionada em razão da participação das mulheres nos esforços de guerra. Com o fim dos conflitos teriam ocorrido campanhas estrangeiras defendendo o retorno das mulheres aos recônditos da vida familiar e a manutenção dos valores tradicionais.

Na próxima seção, o foco direciona-se à análise das representações fotográficas sobre as moças modernas formadas na ESERD. Propomos percorrer as "vidas pregressas" de imagens que referenciaram aspectos da vida escolar ao longo do recorte cronológico, entre as décadas de 1950 e 1970, por meio de uma hermenêutica das temporalidades e espacialidades da fotografia. Em síntese, pretendemos transitar entre as superfícies das imagens, o que se apresenta à vista, e o que elas silenciam, entre memórias e esquecimentos.

\section{A Escola de Economia Rural Doméstica em foco}

A fotografia surge em meio à modernidade do século XIX. Para os propósitos de uma breve contextualização, nos referimos a um tempo e ambiente que abrangem sensíveis transformações - culturais, sociais e políticas nas formas de apreensão da realidade. Nesse contexto, a invenção da fotografia multiplicou as possibilidades de informação e conhecimento. Demandou o aperfeiçoamento contínuo de novas técnicas, equipamentos e materiais para atender ao consumo crescente de uma clientela ansiosa pela posse de retratos, cartões-postais, álbuns de família, vistas urbanas. Quase nada escapou às lentes 
dos fotógrafos: guerras, catástrofes, as cidades, a morte, paisagens, festas, exposições científicas, invenções modernas, revoluções, a natureza, os próprios fotógrafos retratados. Face ao desejo de captar a experiência humana,

O mundo tornou-se de certa forma "familiar" após o advento da fotografia; o homem passou a ter um conhecimento mais preciso e amplo de outras realidades que lhe eram, até aquele momento, transmitidas unicamente pela tradição escrita, verbal e pictórica. Com a descoberta da fotografia e, mais tarde, com o desenvolvimento da indústria gráfica, que possibilitou a multiplicação da imagem fotográfica em quantidades cada vez maiores através da via impressa, iniciou-se um novo processo de conhecimento do mundo, porém de um mundo em detalhe, posto que fragmentário em termos visuais e, portanto, contextuais (KOSSOY, 2001, p. 28).

A massificação e os aperfeiçoamentos nas formas de reprodução gráfica possibilitaram a veiculação da imagem fotográfica em larga escala. Iniciava-se assim um novo processo de conhecimento do mundo e das sociedades apoiado na informação visual. A imagem fotográfica, vinculada ao texto escrito, passou a constituir os repertórios informacionais nos quais aspectos, hábitos e costumes de culturas e sociedades se tornaram próximos, conhecidos e colecionáveis, revolucionando a constituição da memória coletiva, pois as tecnologias de representação da realidade se tornaram acessíveis e desejadas, e o mundo, "portátil e ilustrado" (KOSSOY, 2001, p. 29).

Em outros termos, a fotografia é tecnologia, flerta com a arte, é artefato, relicário, meio de subsistência, mercadoria, registro da realidade ou manipulação do acontecido, portanto, um objeto híbrido e polissêmico por natureza, que articula temporalidades e espacialidades, visto que

Temporalmente de fato [...] a imagem fotográfica interrompe, detém, fixa, imobiliza, destaca, separa a duração, captando dela um único instante. Espacialmente, 
da mesma maneira, fraciona, levanta, isola, capta, recorta uma porção de extensão. A foto aparece dessa maneira, no sentido forte, como uma fatia, uma fatia única e singular de espaço-tempo, literalmente cortada ao vivo. Marca tomada de empréstimo, subtraída de uma continuidade dupla (DUBOIS, 1993, p. 161).

Sob esse enfoque, a imagem fotográfica, para além de impressão luminosa, é impressão resultante de um gesto radical, de um corte que a materializa por inteiro. Por um lado, esse corte interrompe e eterniza o instante impresso em cada imagem, parecendo frear a existência e conter a ação corrosiva do tempo. Por outro lado, as imagens captadas e acomodadas em suporte material sugerem a captura da totalidade espacial que o fotógrafo desejou enquadrar com a sua câmera. No entanto, em ambas as situações há fissuras e vazios, por se tratar de fatias, de cortes resultantes dos golpes sucessivos do click fotográfico.

Os clicks fotográficos da ESERD evocam imagens da vida escolar. Ao passo que a memória de uma instituição está permeada por diversas imagens, vamos abranger repertórios recorrentes nas representações fotográficas da escola, circunscritas às sociabilidades da educação profissional feminina. As temáticas compreendem aspectos do cotidiano escolar relacionados aos ritos de celebração, atividades pedagógicas e sociabilidades.

A Figura 1 resgata imagens das formaturas, eventos que representam a culminância da trajetória escolar: 
Juno Alexandre Vieira Carneiro p. $135-154$
A moça moderna nas Fotografias da Escola de Economia Rural Doméstica de Uberaba (ESERD)

Figura 1 - Coleção de fotos da ESERD: formaturas

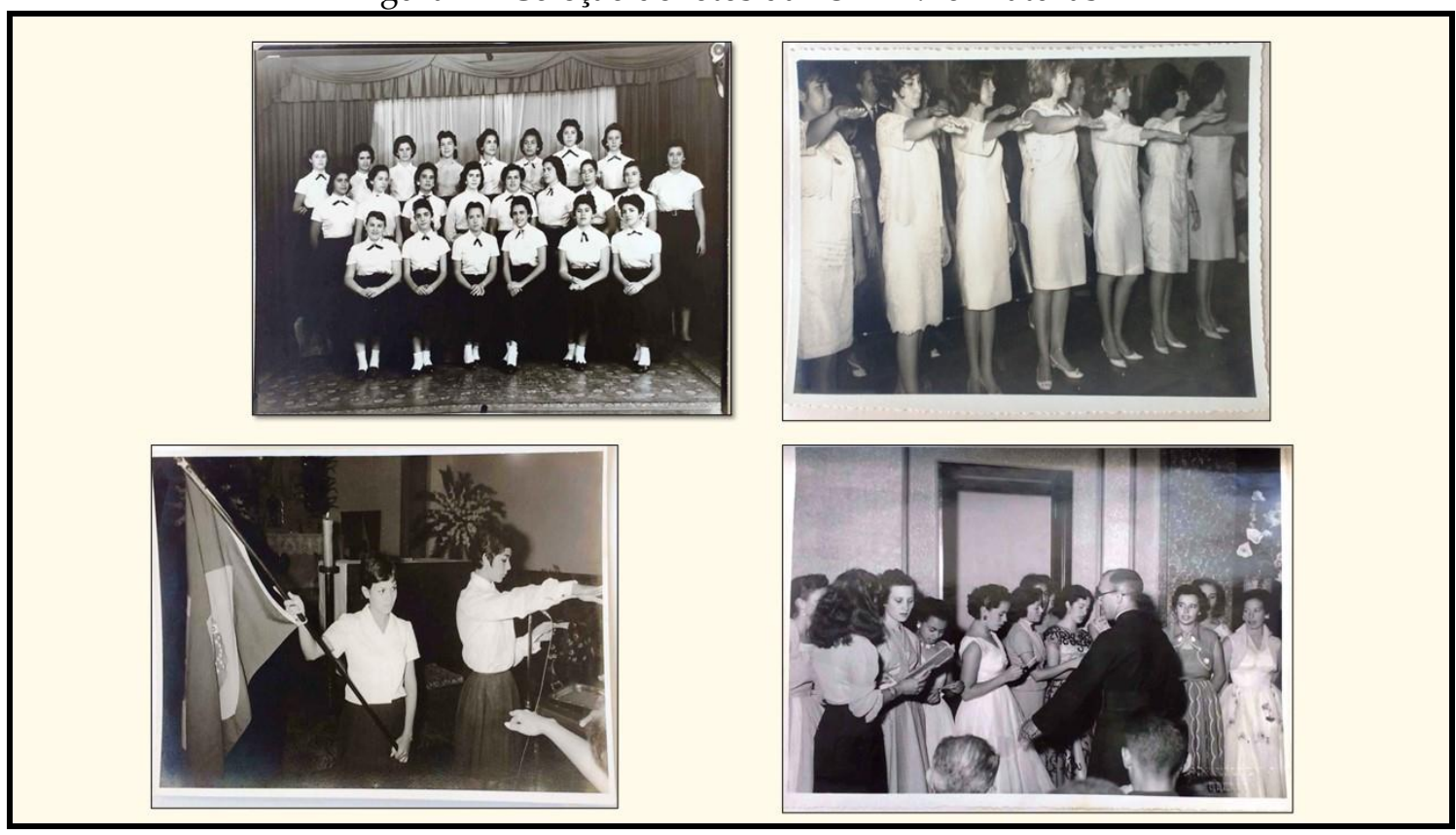

Fonte: Arquivo Histórico do IFTM - Campus Uberaba

No calendário anual, as formaturas destacam-se como momentos solenes cuidadosamente planejados pelo corpo dirigente e ansiosamente aguardados pelos alunos e familiares. De fato,

A escola reafirma o ritual, impregnando na comunidade (e em nosso olhar) sua autoridade e competência na formação dos indivíduos. Nas imagens das formaturas, a comunidade se curva e aceita o poder social da escola. Nas fotos desses eventos encontram-se signos da escola como veículo promotor de ascensão social (BARROS, 2005, p. 126).

A formatura é o rito de passagem legitimado socialmente. Demarca o tempo da maturidade construído em uma trajetória permeada por elementos discursivos de forte apelo simbólico: renúncias, sofrimento, alegrias, laços de amizade, agradecimentos, esforço e dedicação fundamentam os conteúdos da oratória ao longo da cerimônia. As imagens da Figura 1 captam as etapas da fotografia coletiva das formandas, o juramento e uma apresentação de canto 
coral. O que "salta aos olhos" do observador nessas fotografias são as expressões delicadas e compenetradas, as indumentárias sóbrias e os enquadramentos que valorizam o protagonismo das formandas.

A evocação das memórias das celebrações da ESERD acompanha paripassu a dificuldade de revelar as ausências, de dar a conhecer o que está implícito no cotidiano escolar. É provável que as imagens da Figura 1 tenham sido reproduzidas e adquiridas pelas formandas, portanto, teriam sido objeto de outros usos e apropriações. Podemos sugerir que as representações fotográficas cumpriram função central na difusão de valores que exaltavam a eficácia e a relevância da instituição para a cidade de Uberaba. Por certo, a formação em economia rural doméstica oferecida pela ESERD voltou-se especificamente ao público feminino objetivando a instrução ancorada na ação educativa, mas, sobretudo na preparação das moças modernas para o exercício dos deveres maternais, domésticos e sociais (FERREIRA, 2014, p. 134).

Em seguida, observemos a Figura 2, que reúne atividades teóricas e práticas na ESERD:

Figura 2 - Coleção de fotos da ESERD: aspectos das aulas teóricas e práticas

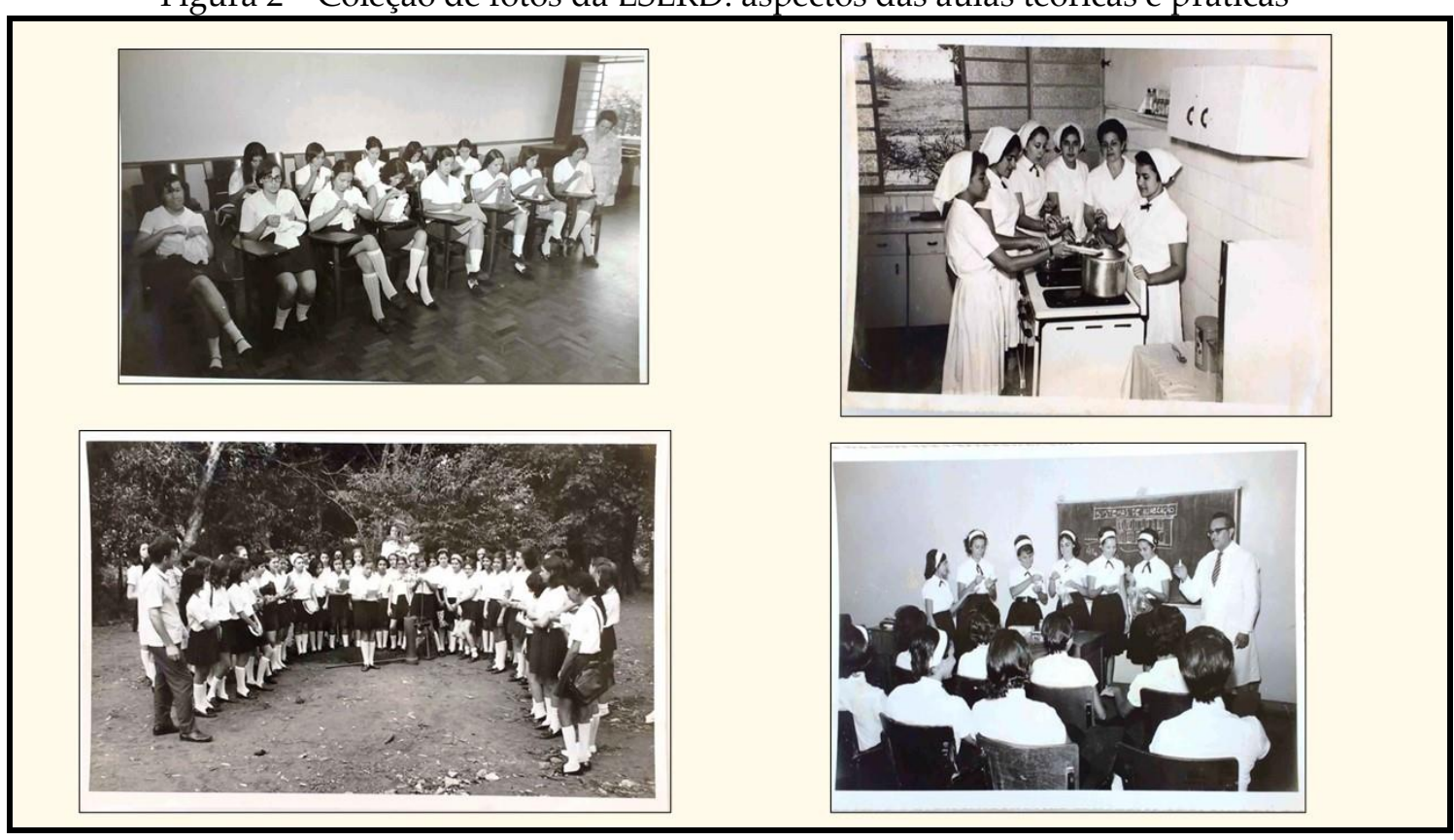

Fonte: Arquivo Histórico do IFTM - Campus Uberaba 
Juno Alexandre Vieira Carneiro

p. $135-154$
A moça moderna nas Fotografias da Escola de Economia Rural Doméstica de Uberaba (ESERD)

As imagens captam flagrantes do cotidiano, cenas aparentemente “triviais" de uma instituição de ensino, no entanto:

As fotografias produzidas pelas instituições falam de uma história oficial, produzidas para o governo [...] ou para mantenedoras religiosas ou laicas, no caso das instituições particulares. As fotos são principalmente construídas por fotógrafos profissionais, associando uma estética apurada no tratamento formal (com planos bem construídos e distribuição da figuração) com um conteúdo fundado em signos que remetem à tradição humanista secular e à disciplina moral e religiosa (BARROS, 2005, p. 121-122).

Sob o aspecto dos elementos formais das imagens - composição, enquadramento, planos e disposição - percebemos a preparação prévia às tomadas. Os enquadramentos sugerem a centralidade nas atividades de ensino, com as presenças dos professores, símbolos da autoridade do saber, em três imagens. Na aula de bordado, as fileiras estão dispostas lado a lado, com destaque para a profundidade de campo obtida pela mirada em perspectiva, assim como na atividade ao ar livre. As janelas semiabertas emolduram os enquadramentos, espécie de quadro que suaviza a formalidade dos personagens e objetos da sala de aula.

Recuperando os argumentos de Armando Martins de Barros acima, a ESERD tratou de incorporar em seu projeto pedagógico a disciplina de formação familiar. De acordo com o relato de uma aluna do $2^{\circ}$ ano colegial:

Muito importante esta matéria. São abordados todos os aspectos da vida: moral, social, econômico. Nosso orientador, Pe. Eddie é um grande conhecedor do assunto. Ajuda, inclusive, em nossos problemas pessoais, orientando as alunas e esclarecendo o caminho da verdade. Diferença de outros colégios? Existe, sim [...] Aqui, há um clima de achego entre professores e alunos [...] E ainda mais: há no colégio 
uma verdadeira preparação para se enfrentar a vida (CORREIO CATÓLICO, 1968, p. 6).

A passagem faz parte de extensa matéria intitulada: “Economia Doméstica, um sorriso em cada canto", assinada por Jorge Zaidan e ilustrada com imagens de Ricardo Prieto, um dos fotógrafos que prestou serviços à escola ${ }^{9}$. Desde os primórdios da ESERD, a preparação para a vida foi cuidadosamente estimulada por meio da formação técnica, mas também se voltou aos aspectos éticos e morais em consonância com os dogmas da Igreja Católica. A esse respeito, a atuação do Padre Eddie Bernardes parece ter sido central no que tange à orientação educacional mencionada pela aluna acima. Por certo, o "caminho da verdade" era reforçado por uma expressão cunhada ainda em 1954 pela oradora da primeira turma de magistério em Economia Rural Doméstica: "A família é o núcleo fundamental da sociedade humana" (RELATÓRIO DE ATIVIDADES DA ESERD, 1955, s.p.), assegurada pela solidez e perenidade do matrimônio que, conclui a referida oradora, longe de se limitar a uma benção, representa um verdadeiro sacramento. Essa vocação para a vida conjugal seria inerente ao universo feminino, ao passo que:

A mulher que não seguisse seus caminhos estaria indo contra a natureza, não poderia ser realmente feliz ou fazer com que outras pessoas fossem felizes. Assim, desde criança, a menina deveria ser educada para ser boa mãe e dona de casa exemplar. As prendas domésticas eram consideradas imprescindíveis no currículo de qualquer moça que desejasse se casar. E o casamento, porta de entrada para a realização feminina, era tido como "o objetivo" de vida de todas as jovens solteiras (BASSANEZI, 2004, p. 510).

\footnotetext{
${ }^{9} \mathrm{Na}$ etapa de catalogação arquivística fomos confrontados com o desafio de identificar a autoria de algumas imagens, por meio de análises comparativas dos elementos técnicos e estéticos que nos asseguram a atribuição do produtor. Podemos afirmar a ocorrência de três profissionais com significativa produção sobre a escola: Kazuo Oshio, João Schroden Jr. e Ricardo Prieto, o que nos leva a sugerir um circuito social de fotógrafos profissionais que prestaram serviços em muitos momentos da trajetória da ESERD.
} 
Ou seja, nessa passagem - e na matéria do Correio Católico - a palavra "caminho" demarca o ideal de felicidade reservado à mulher. Caberia a ela a condução da família por caminhos pavimentados com os alicerces de uma boa formação profissional e espiritual, ambas oferecidas pela ESERD, mas legitimadas pelo sacramento do matrimônio.

Ao longo da pesquisa documental observamos o predomínio de narrativas sobre a preservação e defesa de valores tradicionais, o que reforça a hipótese de que ao longo da existência da ESERD, em que pesem as sensíveis transformações estruturais da sociedade brasileira, o corpo dirigente soube preservar aqueles valores que demarcavam o sentido de missão das moças modernas formadas pela escola. Nilce Vieira Campos Ferreira (2014) argumenta que as orientações abrangiam dinâmicas de grupo e atendimentos individuais, em auxílio à solução de problemas pessoais e familiares. Nesse sentido, "O orientador não dizia como fazer ou o que fazer, mas sugeria possíveis fontes de informação para a moça tomar suas decisões" (FERREIRA, 2014, p. 298).

A finalidade da disciplina de formação familiar voltava-se ao despertar do espírito comunitário, assim como para o sentimento de pertencimento coletivo, uma vez que o grupo deveria ser entendido como prolongamento do indivíduo, com especial atenção à formação das virtudes sociais, da compreensão humana e solidariedade - esta virtude geralmente traduzida em ações caritativas, tendo como espelhamento das ações "políticas" das primeiras damas.

Há nessas ideias a naturalização da coletividade como condição para a preservação e reprodução da vida. Recuperando os dois relatos anteriormente analisados, entre 1954 e 1968, percebemos a força das representações coletivas, como demonstrado na Figura 2, no sentido de explicitar imagens de forte conteúdo simbólico, por meio da coesão social dos grupos de alunas. Assim, as interações entre a imagem fotográfica e os discursos parecem convergir para a 
leitura da ESERD enquanto instituição habilitada ao enfrentamento das vicissitudes da existência individual e da coexistência comunitária, por meio da eficácia da orientação educacional oferecida pela instituição.

A próxima figura destaca momentos de socialbilidades proporcionados pela ESERD. Considerando as posturas e expressões das alunas, as imagens demonstram preparação prévia à tomada por parte dos fotógrafos, pois as poses não revelam movimento e/ou espontaneidade das retratadas. Quanto ao núcleo temático central, a Figura 3 evidencia atividades de comemorações, visitas técnicas e práticas esportivas.

Figura 3 - Coleção de fotos da ESERD: sociabilidades

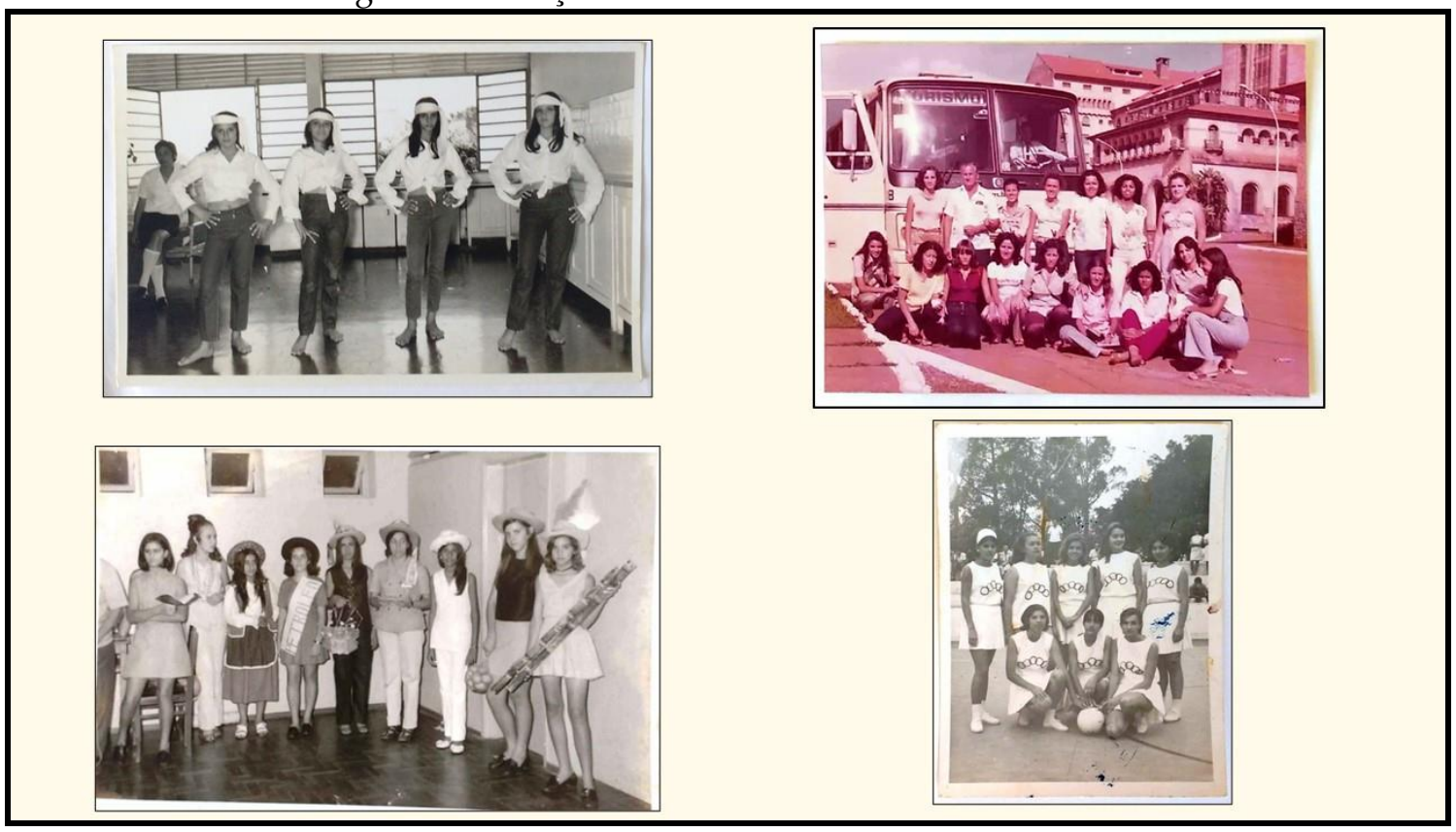

Fonte: Arquivo Histórico do IFTM - Campus Uberaba

São manifestações que estimulam o sentimento de unidade e coesão identitárias e, assim como a formação profissional stricto sensu, os momentos de comunhão entre alunos, dirigentes e a sociedade demarcam o calendário anual escolar, de tal modo que: 
Estabelecer um calendário é acalmar, organizar o tempo, como alguém que constrói represas para regular o curso de um rio; É adquirir a impressão de dominar, regulando o inelutável. A contemplação de um calendário evoca o reinício perpétuo. É o símbolo [...] da ordem inteligível que preside o fluxo do tempo; É a medida do movimento (CHEVALIER, 1986, p. 236).

Este autor nos faz pensar no calendário como o símbolo de um ciclo de iniciação e renovação, pontuado por atribuições específicas do fazer escolar: matrículas, avaliações, exames finais, trabalhos, visitas técnicas, mas também permeado por datas cívicas, religiosas, atividades assistencialistas, culturais e sociais. De fato, a ESERD reservou atenção especial às comemorações como indissociáveis à formação em Economia Rural Doméstica. Com efeito, os eventos organizados pelos professores e pelas próprias alunas comportavam a dimensão pedagógica, quer seja na articulação aos conteúdos formais, quer seja na apreensão de valores morais, religiosos e patrióticos.

Em se tratando da ESERD, os eventos cívicos exaltavam os valores nacionais, pautados em uma cultura política alicerçada em princípios republicanos de ordem e progresso (FERREIRA, 2014, p. 361). São fotografias higienizadas, idealizadas para reforçar os laços de pertencimento entre alunos e dirigentes, e destes com a sociedade local. Não por acaso, os registros evocam imagens de solidariedade e pertencimento, resultando em repertórios imagéticos que dialogam com a retórica nacionalista das décadas de 1960 e $1970^{10}$. Os "roteiros imagéticos" da Figura 3 enfatizam o cuidado conferido à

\footnotetext{
${ }^{10}$ Lilia Moritz Schwarcz e Heloisa Murgel Starling sustentam que o controle coercitivo por si só, não teria garantido o apoio da sociedade ao regime militar. Então, a partir de 1969, a Assessoria Especial de Relações Públicas (AERP), foi responsável por realizar: “Uma campanha de propaganda política sem precedentes. A propaganda era criativa, não tinha nada de chapa-branca nem ostentava os sinais típicos do marketing político. As peças falavam em otimismo, orgulho e grandeza nacional; celebravam a diversidade e a integração racial brasileira; afirmavam a harmonia social, e embalavam tudo isso em filmes curtos, com narração direta, imagens bem cuidadas e um arremate musical que grudava na lembrança do espectador". Conferir: (SCHWARCZ; STARLING, 2015, p. 453-454).
} 
memória institucional pela ESERD. Por certo, ao percorrermos a totalidade do acervo fotográfico da ESERD, em torno de 500 fotografias entre as décadas de 1950 e 1970 constatamos a existência de outros roteiros fotográficos que cumpriram funções primordiais para a instituição. Ao longo das transformações - Escola Agrotécnica Federal de Uberaba (EAFU), (CEFET) e a partir de 2008 (IFTM) - mudaram os atores e os roteiros, mas as demandas pela produção e difusão de imagens não cessaram.

Finalmente, os registros fotográficos da ESERD preservados no arquivo histórico do IFTM Campus Uberaba são janelas para a percepção das condições sociohistoricas, ao colocarem em evidência: elementos da história das técnicas e tecnologias, o que permite pensar as transformações no mundo do trabalho e das sociabilidades; as permanências e mudanças que caracterizam o ensino técnico e profissionalizante, bem como as práticas culturais e pedagógicas em foco.

Em relação às "protagonistas" deste texto, percebemos uma situação pendular da figura feminina, ora estimulada a emancipar-se, tornar-se moderna e contribuir para o desenvolvimento econômico através da gestão científica do lar e da família, ora limitada por valores tradicionais e patriarcais com vistas à preservação de padrões éticos e morais.

Logo, a via de entrada das moças da ESERD no turbilhão da modernidade de meados do século XX caracterizou-se pela formação pautada em critérios científicos e racionais, mas circunscritos ao espaço doméstico. Nele, as moças modernas exerceriam as funções de gestoras do lar, boas mães e esposas cientes da missão de proporcionar estabilidade e harmonia ao núcleo familiar. 
Juno Alexandre Vieira Carneiro

p. $135-154$

\section{Referências bibliográficas}

ARQUIVO HISTÓRICO DO IFTM CAMPUS UBERABA (Brasil). Relatório de atividades da ESERD. Uberaba: IFTM/Campus Uberaba, 1955.

BARROS, Armando Martins. Os álbuns fotográficos com motivos escolares: veredas ao olhar. In: GATTI Jr., Décio e INÁCIO FILHO, Geraldo (orgs.). História da educação em perspectiva. Ensino, pesquisa, produção e novas investigações. Campinas, SP: Autores Associados; Uberlândia, MG: EDUFU, 2005.

BASSANEZI, Carla. Mulheres dos Anos Dourados. In. DEL PRIORE, Mary (org.); BASSANEZI, Carla. (coord. de textos). 7. ed. História das mulheres no Brasil. São Paulo: Contexto, 2004

BITTAR, Marisa, BITTAR, Mariluce, História da Educação no Brasil: a escola pública no processo de democratização da sociedade. Acta Scientiarum Education [en linea] 2012, 34 (Julio-Diciembre): [Data de consulta: 5 de julho de 2019]. Disponível em:http://awww.redalyc.org/articulo.oa?id=303325733002.

CHEVALIER, Jean e GHEERBRANT, Alain (orgs). Diccionario de los símbolos. Barcelona: Editorial Herder, 1986.

CORREIO CATÓLICO. Economia Doméstica, um sorriso em cada canto. Uberaba, 18 de novembro de 1968, p. 6.

DUBOIS, Philippe. O ato fotográfico. 5. ed. Campinas: Papirus, 1993.

FERREIRA, Nilce Vieira Campos. Economia doméstica: Ensino profissionalizante feminino no triângulo mineiro. (Uberaba/MG - 1953-1997). Jundiaí: Paco Editorial, 2014.

KOSSOY, Boris. Fotografia e História. 2. ed. São Paulo: Ateliê Editorial, 2001.

LAVOURA E COMÉRCIO. Será solenemente instalada amanhã a Escola de Economia Doméstica. Uberaba, 8 de agosto de 1953, p.1.

LEMES, Luciana Couto. O modelo de gestão das Escolas Agrotécnicas Federais, Centros Federais de Educação Tecnológica e Institutos Federais de 
Educação, Ciência e Tecnologia: um estudo de caso do IFTM Campus Uberaba. Dissertação de Mestrado. Programa de Pós- Graduação - Mestrado Profissional em Educação Tecnológica. Uberaba: IFTM, 2016.

SCHWARCZ, Lilia Moritz; STARLING, Heloisa Murgel. Brasil: uma biografia. São Paulo: Companhia das Letras, 2015. 